\title{
Saberes que se Encontram: reflexões sobre uma experiência de troca com Mestre Biu Alexandre
}

\begin{abstract}
Resumo
Este artigo tem como objetivo refletir, a partir da experiência vivenciada pelas autoras, sobre os diálogos e as trocas entre saberes acadêmicos e saberes tradicionais proporcionados pela atuação do Mestre Biu Alexandre, do Cavalo Marinho de Condado/PE, como um dos professores da disciplina Artes e Ofícios dos Saberes Tradicionais. Esta disciplina é ministrada na Universidade de Brasília desde 2010 como parte do Projeto Encontro de Saberes, que visa o reconhecimento de mestres de diversas tradições como docentes no ensino superior.
\end{abstract}

Palavras-chave: saberes tradicionais, Cavalo Marinho, tradição, brincadeira, epistemologia.

Abstract

This article aims to reflect, from the experience of the authors on the dialogues and exchanges between academic knowledge and traditional knowledge provided by the agency of Master Biu Alexander, Cavalo Marinho Estrela de Ouro / PE - Brazil, as one of the professors of Arts and Crafts of Traditional Knowledge. This course is being taught at the University of Brasília since 2010 as part of Project Encounter of Knowledge, which aims to recognize teachers of various traditions as teachers in university.

Key-words: tradicional knowledge, Cavalo Marinho, tradition, epistemology

"Vocês vão ver, mas o negócio é entender".

- Mestre Biu Alexandre - Condado/PE

Mestre Biu Alexandre, do Cavalo Marinho Estrela de Ouro, da cidade de Condado Pernambuco, foi nosso professor. A disciplina Artes e Ofícios dos Saberes Tradicionais, realizada em sua primeira edição no segundo semestre de 2010, como iniciativa pioneira da Universidade de Brasília, viabilizou o encontro e a troca de saberes de alunos e professores universitários com mestres de culturas tradicionais. Os mestres tornaram-se professores universitários e nós, professoras-parceiras do projeto, suas alunas. Este artigo, mais do que uma reflexão profunda sobre todas as - importantes - questões metodológicas e epistemológicas que envolveram o processo de realização da disciplina, deve assumir a forma de um relato de experiência. Uma experiência acadêmica, artística, intelectual e, sobretudo, uma experiência compartilhada, corporal, sensorial e afetiva. 
Nossa participação no Projeto Encontro de Saberes ${ }^{1}$ teve início no primeiro semestre de 2010, ainda na fase de organização das atividades a serem desenvolvidas com os cinco mestres que participariam da disciplina. É importante frisar nosso envolvimento em todas as etapas do Projeto, desde o Seminário Internacional - que reuniu mestres, professores e administradores públicos que expuseram, refletiram e debateram iniciativas semelhantes que vêm ocorrendo em outros países da América -, passando pela residência dos Mestres em Brasília, até o desenvolvimento da disciplina propriamente dita.

A seguir abordaremos, sob nosso ponto de vista, a realização dessas três etapas, com ênfase na terceira, concernente à disciplina Artes e Ofícios dos Saberes Tradicionais, no intuito de compartilhar um pouco dessa experiência e das reflexões delas suscitadas. Devemos salientar, ainda, que para este exercício reflexivo optamos por dialogar diretamente com Mestre Biu, através de suas falas e depoimentos, e com os registros dos alunos que participaram da disciplina, colocando em segundo plano, propositalmente, a bibliografia que trata do Cavalo Marinho. Consideramos que essa opção seja coerente com a proposta de reposicionamento de saberes a que o Projeto - e este artigo - se propõe.

Comecemos pelo Seminário. A participação, no auditório Dois Candangos, da Faculdade de Educação/UnB, da aula inaugural do Seminário Internacional $A$ inclusão das Artes e dos Saberes Indígenas, Afro-Americanos e Tradicionais na Universidade, com a presença de Mapulu Kawayurá, pajé do Alto Xingu, falando sobre o seu povo e a sua conexão com a ancestralidade e espiritualidade, representou um momento especial em nossa trajetória de pesquisa e ensino na Universidade de Brasília. A xamã trouxe para o espaço acadêmico a fumaça oriunda de uma folha de fumo que o grupo cultiva, e naquele momento houve uma transformação na ambiência da sala. Ela colocou-se como conectada ao seu pai, Mestre Takumã - Kamayurá, decano dos xamãs da região, que se encontrava doente e não pôde comparecer ao evento, e suas palavras ecoaram dentro do espírito da tradição e da relação com o seu povo. A própria maneira com que as palavras, na língua kamayurá, eram traduzidas para o português, por seu sobrinho, que falava em um ritmo lento e cadenciado como o dela e não com a costumeira pressa e aceleração das traduções simultâneas, fazia com que nos situássemos em outra dimensão de tempo e espaço. Dentro de uma linhagem de tradição mestre e discípulo, ela se apresentava como detentora dos saberes ancestrais e como ligação de nosso tempo atual com dimensões sagradas.

Em outro momento do Seminário, a líder guarani Maria Luísa Duarte Medina, que atua na Secretaria de Assuntos Indígenas do Estado Paraguaio e em projetos de inclusão dos saberes indígenas nas instituições paraguaias de ensino, explicou ao público presente, composto majoritariamente de alunos e professores universitários, que seu povo percebe o homem como parte da natureza, situa a selva como sua casa, as rochas como tendo vida e considera que tudo está integrado. Para os guarani, segundo ela, a diversidade é a essência da riqueza. A natureza é a mãe, as plantas são detentoras de poder e os conhecimentos de botânica são ancestrais. Fundamentalmente sua conferência demonstrou como a universidade paraguaia tem buscado outras referências, que não só o modelo europeu, para criar um ambiente acadêmico que contemple a diversidade de conhecimentos e tradições.

\footnotetext{
${ }^{1} \mathrm{O}$ Encontro de Saberes é um projeto que visa promover o diálogo entre os saberes acadêmicos e os saberes indígenas, afro-brasileiros e tradicionais em geral para o processo de reconhecimento de mestres dessas tradições como docentes no ensino superior, aliando esses dois universos por meio da realização de cursos regulares nas universidades e de outras ações interculturais. O projeto foi idealizado e é coordenado pelo prof. Dr. José Jorge de Carvalho, da UnB, e conta com o apoio do CNPq, através do INCT (Instituto Nacional de Ciência e Tecnologia) Inclusão no Ensino Superior e na Pesquisa. Em sua primeira edição o projeto também contou com a parceria da Secretaria da Identidade e da Diversidade Cultural (SED/MinC) e do Ministério da Educação, por meio da Secretaria de Educação Continuada, Alfabetização e Diversidade (Secad/MEC).
} 
Trouxemos aqui, dadas as limitações de espaço concernentes a um artigo, apenas dois momentos exemplares do Seminário, ocorrido entre os dias 13 e 15 de julho de 2010, que contou com a presença de representantes de diversas tradições indígenas e afro-brasileiras ${ }^{2}$. De qualquer forma, em comum pudemos perceber, nas transmissões orais das diferentes personalidades e culturas presentes, o foco na tradição, na ancestralidade, na espiritualidade, na relação entre mestre e discípulo e na percepção de que a experiência não pode ser vivenciada como algo fragmentado. Por que nos parece dissonante, em um primeiro momento, falar de espiritualidade no contexto acadêmico? Estamos tão habituados a dissociar e segmentar os saberes, categorizá-los em disciplinas com suas ementas específicas, que nos parece estranho falar de um lugar que busca uma integração entre sentir, pensar e fazer. O Seminário, por fim, resultou como um convite a reatar, reconectar, relembrar, religare.

Foi no momento da Residência dos Mestres - $2^{a}$. etapa do projeto - que começamos a travar um contato mais direto com o Mestre Severino Alexandre da Silva, conhecido como Biu Alexandre. Mestre Biu conheceu as diversas dependências da UnB e logo participou de uma aula da disciplina Teatralidades Brasileiras, ministrada no Curso de Artes Cênicas. No horário marcado nós, as professoras-parceiras, fomos recebê-lo na porta da sala de aula, mas ele pediu que entrássemos antes e o aguardássemos. Ele então faz uma entrada triunfal, desfilando pelo espaço com sua camisa de cetim florida e sua boina características, exibindo um grande sorriso, distribuindo cumprimentos e demonstrando grande domínio do "público", nossos alunos (de várias outras disciplinas também) que lotavam a sala de aula. Desde o primeiro momento todos ficaram maravilhados. Que Mestre Biu é um grande performer - ou, melhor dizendo, na sua linguagem, brincante não tivemos dúvida.

Ele começou a interação com a turma falando sobre a sua trajetória, contando que há 54 anos brinca o Cavalo Marinho e explicando que essa é uma expressão cultural que vem de Pernambuco, em grande parte ligada ao universo dos trabalhadores da canade-açúcar, do qual ele próprio fez parte. Quando perguntado pelos alunos sobre como havia aprendido o Cavalo Marinho, ele surpreendeu dizendo que ninguém the ensinou, que aprendeu olhando os outros: "A pessoa olhando aprende primeiro do que fazendo". Conta então que seu pai foi um grande mestre do Cavalo Marinho, que começou brincando e só depois passou a "mestrar". Ele próprio aprendeu de tanto ver a brincadeira, desde os seis, sete anos, escondido debaixo das saias de sua mãe, mas só começou a "botar figura" com 13 anos de idade, fugido de seu pai, pois este não o deixava brincar. Em entrevista à pesquisadora e atriz Ana Caldas Lewinsohn (2009: 8283), Mestre Biu aprofunda a questão de seu aprendizado:

Eu não ensino nada a ninguém. A ninguém, nem a filho, nem a neto, nem a você se vier aprender comigo, não vai aprender, eu não ensino. Você sabe que palavra é essa, dá pra entender? Pra eu ensinar uma coisa a você, o que é que eu vou fazer com você? Pra lhe ensinar e você aprender comigo? Vou pegar suas pernas e dançar! Não é assim? Aí to ensinando? O que a gente faz é dar orientação. Aí tá certo. Se Aguinaldo disser: "olhe pai, ensinei aquela menina ali", eu digo: "você mentiu". É porque ele não sabe? Ele sabe. Mas ensinar não. (...) A gente brinca, a gente dá aquela explicação, faz, a gente dança, que é pra pessoa ver. Mas ensinar ninguém tem esse direito de ensinar ninguém. Certo ou errado? Se estiver errado pode dizer, que eu não me incomodo não.

Em nossa tradição acadêmica como se ensina algo a alguém? Como se dá a transmissão dos saberes? Em muitas situações privilegiamos a cultura da informação em detrimento da cultura da experiência, o professor se posiciona como detentor de um saber a ser repassado para o outro. O que parece evidenciar-se na fala do Mestre Biu é a necessidade de colocar o outro em situação de aprendizado, o saber passa pelo corpo e se apresenta como uma vivência singular para cada pessoa envolvida no processo de aprendizagem. Não se ensina algo a alguém, há uma troca de experiências, brinca-se

\footnotetext{
${ }^{2}$ Maiores informações em: http://www.inctinclusao.com.br/encontro-de-saberes/seminario-internacional
} 
com o outro e os saberes são compartilhados. Para compreender esse processo de troca podemos pensar, junto com a antropóloga Jean Lave (1996), que devemos participar da "comunidade de prática" do Cavalo Marinho, ou seja, precisamos praticar juntos técnicas, expressões, saberes e fazeres para de fato conhece-los. No intuito de levantar alguns aportes teóricos que auxiliem na reflexão aqui proposta, recorremos também ao conceito de "aprendizagem situada", desenvolvido por Lave com o colega Ettiene Wenger (1991) por acreditar que este se mostra bastante operativo para compreender o processo de transmissão e aprendizagem não apenas do Cavalo Marinho, mas também de diversas outras tradições expressivas. Esta abordagem considera que o conhecimento não se constitui de forma abstrata e descontextualizada, apenas como um processo mental, mas como um processo colaborativo que emerge de situações e contextos específicos.

Neste sentido, o ensinamento de Mestre Biu: "ensinar, ninguém tem esse direito de ensinar ninguém" permeou toda nossa participação na disciplina e a reflexão sobre ele será retomada em outros momentos do texto.

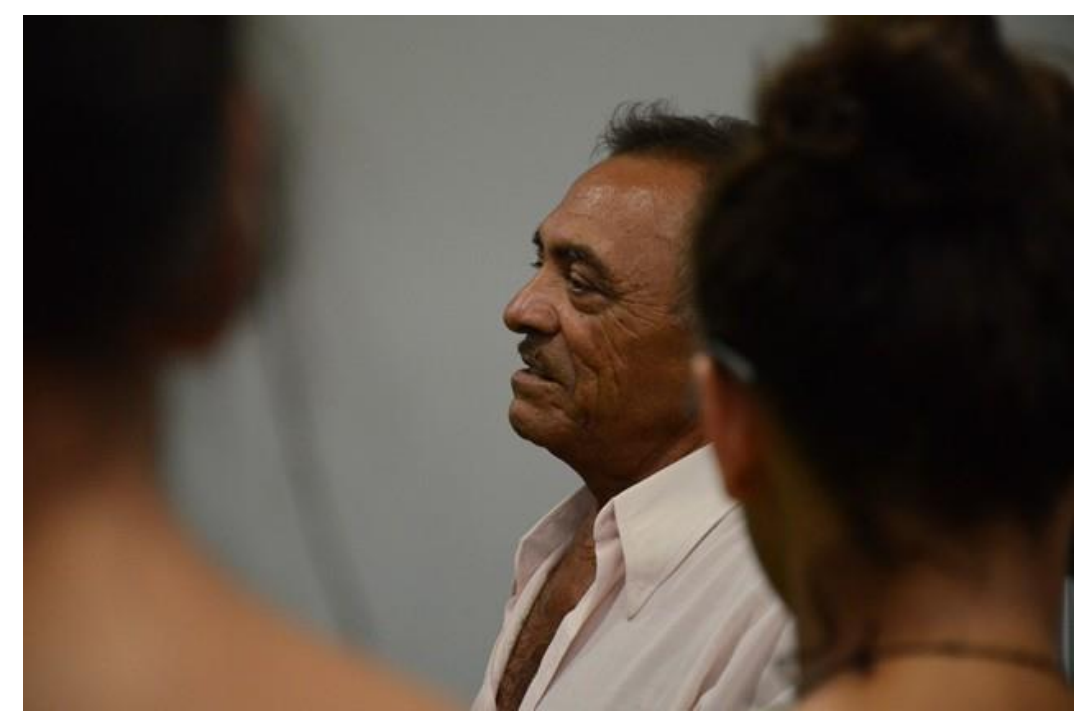

Foto 01: Mestre Biu Alexandre ministrando aula na UnB.

Continuando sua interação com a turma, Mestre Biu explica que antigamente não havia mulheres no Cavalo Marinho e que os meninos brincavam desde criança. A curiosidade no grupo cresce, nossas discussões contemporâneas de gênero vêm à tona e alguém pergunta: "Mas Mestre, mulher não pode brincar o Cavalo Marinho?". Ele então responde, nos surpreendendo novamente: "as minhas filhas eu não deixei brincar, mas hoje as netas brincam. Agora parece que as mulheres gostam mais do que os homens". A tradição parece ser muito mais dinâmica do que possamos conceber. A definição dadapor Foley, que também se refere a um contexto de transmissão oral de sabere s (1995: xii), contempla bem esse caráter processual da tradição, descrevendo a tradição como u $m$ corpo de significados dinâmicos e multivalentes que preserva muito do que um grupo invento $u$, transmitiu e incluiu como necessário, e caracteriza-se pela indeterminação e predisposição a vários tipos de mudanças. Voltando à aula com Mestre Biu, este exibe um trecho do vídeo documentário "Cavalo Marinho Estrela de Ouro" (2007) para que os alunos possam ter uma noção mais clara de como se configura a brincadeira, que é tratada por alguns como auto, folguedo,

reisado ou como desdobramento ou variante do Bumba-Meu-Boi ${ }^{3}$. O Cavalo Marinho é

\footnotetext{
3 Para maiores informações sobre dessas definições que, importante salientar, não são dadas pelos Mestres, mas por diferentes pesquisadores do tema, ver: Abreu (2011), Acselrad (2002), M. S. Oliveira (2006), E. Oliveira (2006), Lewinsohn (2009), Murphy (2008), Tenderini (2003), entre outros. É interessante perceber que, em sua maioria, estes pesquisadores são provenientes das áreas de artes, sobretudo do teatro.
} 
composto de diversas figuras que animam a brincadeira. Devido às frequentes indagações que ouve a respeito das figuras, Mestre Biu esclarece, fazendo uma distinção entre figura e personagem: "A figura não é personagem. A figura está com a máscara. Personagens somos nós humanos. Personagem é o Galante." Vejamos a Loa (verso) desse personagem:

\author{
Loa de galante \\ Cajueiro pequenino \\ Carregado de fulô \\ Eu também sou pequenino \\ Carregado de amor \\ Penso de noite e de dia \\ Não sinto fome nem sede \\ Por ti, amor, rosa verde \\ Suspiro de quando em quando \\ Dizeis por onde andas \\ O que pretende a fazer \\ Por ti me obrigue a morrer \\ Eu serei teu defensor $A$ \\ minha estimada flor \\ Abismo do bem querer
}

O mestre diz conhecer 69 figuras: "tem figuras que eu nunca vi, mas eu sei que existem." Ele considera todas as figuras iguais e brinca, passa por todas elas nas rodas de cavalo marinho. A figura do Ambrósio, por exemplo, vem para a roda para vender as figuras do Cavalo Marinho. O mestre pergunta a ele: "eu sei que o senhor tem uma figura muito boa e eu quero comprar". E assim se desencadeia o diálogo cênico entre eles.

Mestre Biu Alexandre diz que antes o grupo se reunia com o povo e fazia os ensaios. Todo sábado havia um ensaio geral, trajado com as roupas, que ia de 9 da noite às 6 da manhã. Agora o grupo se apresenta só no final do ano, em um encontro de Cavalos Marinhos, no Natal, dia 25 de dezembro, em Tabajara, no interior de Pernambuco, ou a convite, em outros eventos, nos quais o Mestre reclama que é destinado pouco tempo para a realização da brincadeira. Hoje, são 21 pessoas que brincam o cavalo marinho Estrela de Ouro. A menção aos ensaios nos desperta para algo que a pesquisadora e profa. de Teatro da UNIRIO Betti Rabetti tem enfatizado em seus trabalhos: as tradições populares são detentoras de um valioso repertório técnico e é nesse sentido que têm de ser valorizadas, ou seja, não por seu "talento natural", mas por sua capacidade de criação, manutenção e transmissão de técnicas específicas (RABETTI, 2000).

Mestre Biu narra ainda duas experiências singulares vividas pelo Grupo: a participação no Brasil em Cena, na Alemanha, em 2006, na qual levaram alguns integrantes do Cavalo Marinho Estrela de Ouro para Berlim e a sua contribuição e atuação no espetáculo cênico $A$ Barca, com direção de Maria Paula Costa Rêgo, em Recife, em 2010. A participação direta do Grupo em um espetáculo teatral demonstra um tipo de conduta ética infelizmente ainda rara no meio teatral brasileiro, no qual, com maior frequência, pesquisadores-artistas realizam suas pesquisas de campo e aprendizado técnico de tradições expressivas e reproduzem-nas descontextualizadamente, num processo mais de apropriação do que de troca e diálogo efetivo, como apontam Carvalho $(2004,2008)$ e Rabetti $(2000)$ em seus trabalhos.

A curiosidade da turma cresce e alguém pergunta sobre a origem do Cavalo Marinho, se teria alguma aproximação com a Commedia Dell'Arte italiana. O Mestre então, com a maior tranquilidade, e sempre estampando um sorriso maroto, afirma que não pode dizer como começou, que sabe que seu pai já brincava, mas que ele só pode falar do que viu. Tanto a pergunta quanto a resposta nos levaram a longas reflexões, 
compartilhadas também com os alunos: por que temos essa necessidade de justificar uma tradição nossa, brasileira, através de uma tradição europeia? Está claro que os contágios, as influências, sempre existiram em todas as formas de manifestação expressiva (e não apenas nestas), mas de onde vem essa angústia pela origem? Seria a origem (se de fato ela existir) mais importante que os processos de transformação e de atualização da tradição?

Foi na terceira etapa do projeto, de realização da disciplina Artes e Ofícios dos Saberes Tradicionais, que esta proposta de virada metodológica e também epistemológica proporcionada pelo projeto nos levou a uma série de questionamentos, muitos ainda sem resposta. A primeira edição da disciplina foi ofertada no segundo semestre de 2010, com carga horária de $90 \mathrm{~h} / \mathrm{a}$. A procura dos alunos dos mais diversos cursos da universidade foi tão grande que, de .uma turma inicial, prevista para acolher

35 alunos (incluindo 3 cotistas negros e 2 indígenas), foram ampliadas as vagas e abertas duas turmas, em turnos diferentes, totalizando 70 alunos inscritos.

Naquele momento participaram cinco Mestres, representando diferentes tradições, etnias, gêneros e regiões do país. Os Mestres, na ordem em que participaram da disciplina, foram: Biu Alexandre/PE; Zé Jerome, Mestre do Congado de Moçambique e de Folia de Reis, da cidade de Cunha/SP, cujo professor parceiro foi Antenor Ferreira, do Curso de Música; Lucely Pio, Mestra raizeira da Comunidade Quilombola do Cedro (GO), acompanhada pela profa. parceira Silvéria dos Santos, do Curso de Enfermagem; Mestre Benki Pianko Ashaninka, do Acre, acompanhado pela profa. Nina Laranjeira, do Curso de Educação Ambiental e Maniwa Kamayurá, arquiteto tradicional e pajé do Xingu, que foi acompanhado pelo professor parceiro Jaime Almeida, do Curso de Arquitetura. Cada Mestre ministrou um módulo de seis aulas, ou duas semanas, e houve ainda um sexto módulo no qual os alunos puderam debater e refletir sobre suas experiências, tanto teoricamente (produzindo artigos) quanto na prática (produzindo performances). Os alunos puderam optar pelo produto final que melhor atendesse às suas demandas e anseios. Todos os trabalhos finais foram coletivos e da mesma forma foram atribuídas as notas finais para os alunos: coletivamente. O grupo de professores e a coordenação pedagógica, composta pela antropóloga Maristela Sousa Torres e pela pedagoga Marta Lobo, após muitos debates e reflexões, concluíram que, considerando as especificidades da disciplina, seria mais coerente optar por atribuir uma menção (nota) final igual para todos.

Assim como a realização dos trabalhos finais e a atribuição de notas, outros procedimentos metodológicos aparentemente simples e habituais nos cursos universitários também foram alvo de reflexões e discussões desde o início da disciplina. Vejamos um exemplo: como estávamos no âmbito de uma disciplina universitária, tivemos que apresentar um programa de realização de cada módulo, uma ementa, mas: e a bibliografia? Depois de muitas discussões entre os professores parceiros, a equipe pedagógica, a coordenação do projeto e os mestres, optamos, no caso do Módulo de Mestre Biu, por indicar apenas alguns textos críticos-reflexivos sobre o próprio conceito de tradição e mais especificamente sobre as tradições performáticas afro-brasileiras e ameríndias ${ }^{4}$. Explicamos essa proposta para os alunos da disciplina - não leríamos nada antes e não escreveríamos durante as aulas - justificando que nossa opção se dava, sobretudo, no sentido de valorizar os conhecimentos dos Mestres por eles mesmos, reconhecendo a experiência viva, a troca através da oralidade, a percepção sensorial. A leitura e a escrita viriam depois. O aluno Nicholas Moreira Borges de Castro, do Curso de Antropologia, comenta essa opção em seu diário de bordo ${ }^{5}$ :

\footnotetext{
${ }^{4}$ Textos de José Jorge de Carvalho (2004, 2006 e 2008).

${ }^{5}$ Os diários de bordo foram parte da estratégia metodológica estabelecida para a disciplina. Nestes, que $d$ everiam ser entregues ao final de cada módulo à coordenação pedagógica, os alunos deveriam registrar suas ex periências, inquietações e descobertas, contribuindo para a construção de uma memória pessoal sobre
} 
A dificuldade de compreender o conteúdo e a forma da brincadeira não se davam apenas pela distância cultural entre meu mundo e os mais diversos aspectos do Cavalo Marinho, e nem simplesmente pela velocidade da fala e maneira de pronunciar as palavras do Mestre, mas também pela sua maneira de passar os conhecimentos. (...) Sua didática é evidentemente distinta do que estamos acostumados ao aprender as matérias na escola e no ensino superior. Não houve uma preocupação rígida da parte do Mestre em explicar processos ou relações de causa e efeito dentro da brincadeira, nem de se ater a classificações e descrições detalhadas. Muito pelo contrário, suas aulas eram bastante práticas, voltadas para estimular nossa ação, sobretudo por meio de sucessivas repetições e memorizações das loas usadas na brincadeira. (...) Confesso que durante o período em que este módulo foi realizado eu precisei fazer algumas pesquisas na internet para compreender melhor os elementos e o funcionamento da brincadeira. (...) Nesses momentos de pesquisa refletia se minha sede por buscar compreender o Cavalo Marinho de forma mais explicativa se configurava como uma necessidade ou uma curiosidade. Até que ponto eu precisava racionalizar e entender o Cavalo Marinho para me sentir mais confortável e seguro, como se eu tivesse que saber racionalmente tudo o que estava fazendo nas aulas? (...) No fim das contas fui tentando me preocupar menos com as explicações e mais com as ações e em como meu corpo reagia a essas ações e relações construídas no espaço social das aulas. Coloquei-me na obrigação de sentir mais do que pensar.

Refletindo sobre essa questão, a aluna Camila Paula Soares, do Curso de Artes Cênicas, também escreve: "Esse é um processo completamente 'novo' de forma de aprendizado, somos muito apegados à forma escrita, a confiar na folha de papel e na nossa visão, e de repente ter que abandonar nosso condicionamento material e ter que aguçar a audição é algo um tanto desafiante." A frase da aluna resume com precisão um dos principais aspectos que envolveram o processo de ensino-aprendizagem, ou melhor, de troca concreta (e também abstrata, subjetiva) de saberes previsto na disciplina: o reencontro com a oralidade. O desafio de não poder confiar o registro dos ensinamentos do Mestre à folha de papel remeteu a todos nós, professoras-parceiras, alunas e alunos, a outra forma de experiência e aprendizado.

A dificuldade em lidar com as diferenças metodológicas e epistemológicas, presentes ao longo de toda a disciplina, e as implicações hierárquicas envolvidas na diferenciação entre saberes escritos e orais (ou acadêmicos e tradicionais/populares) também foram objeto de uma importante reflexão por parte da aluna Gabriela Vieira Braga, do Curso de Gestão Ambiental:

Durante as aulas eu não tinha entendido muito bem a diferença entre loas e toadas. $\mathrm{Na}$ pesquisa isso ficou mais claro, os cantos são as toadas e a poesia são as loas. Outro pensamento que me passou foi a questão do "palavreado". Quando o Mestre falava "toada" eu pensava e inclusive me referia no diário como "entoada", acreditando ser o certo, por vir do verbo entoar, mas além de ver nas pesquisas que o termo usado é "toada", me veio à mente que essa seria uma linguagem do meio, assim como cada área da academia tem as suas, e que foi prepotência da minha parte considerar que o Mestre estava usando um termo incorreto. Se fosse um docente comum, eu jamais teria coragem de corrigir um termo usado por ele, acreditando que eu provavelmente não tivesse contato com aquela palavra. Percebi um choque nesse sentido, por mais que eu respeitasse a posição do Mestre Biu como professor, errei ao achar que ele estava usando um termo incorreto, como se eu tivesse mais autoridade que ele no uso da língua portuguesa. Ou será que erro ao dogmatizar o que os professores acadêmicos dizem?

As reflexões dos alunos em seus diários demonstram o impacto da disciplina em sua compreensão dos processos de ensino-aprendizagem. Mais do que um conteúdo diferenciado, os estudantes aprenderam/experenciaram, sem dúvida, metodologias, e constataram que os saberes podem ser construídos de diferentes maneiras - e que nosso

es novos saberes e para a elaboração de reflexões coletivas sobre a própria proposta da disciplina, como procur amos fazer nesse momento. 
sistema universitário, historicamente dividido em disciplinas e "áreas de conhecimento", é apenas uma delas.

Ainda no período de residência, fizemos com Mestre Biu uma visita à Dona Martinha do Côco, do Paranoá (cidade satélite do Distrito Federal). O encontro ocorreu em uma escola pública local e o Grupo Mambembrincantes, que trabalha com cultura popular brasileira, juntou-se à proposta de troca e sugeriu que todos, alunos e professores de diversos níveis, dançássemos e cantássemos uma ciranda. Rapidamente formamos uma roda, ao contrário de Mestre Biu, que permaneceu recostado em um muro e anunciou enfático, sem abandonar seu sorriso maroto: "Não gosto de ciranda". Ao ser perguntado por que, ele explicou: "Não gosto porque eu não sei. Se eu soubesse, gostava." Para nós, uma chave para o conhecimento de Mestre Biu era acessada naquele momento. Precisamos saber para gostar.

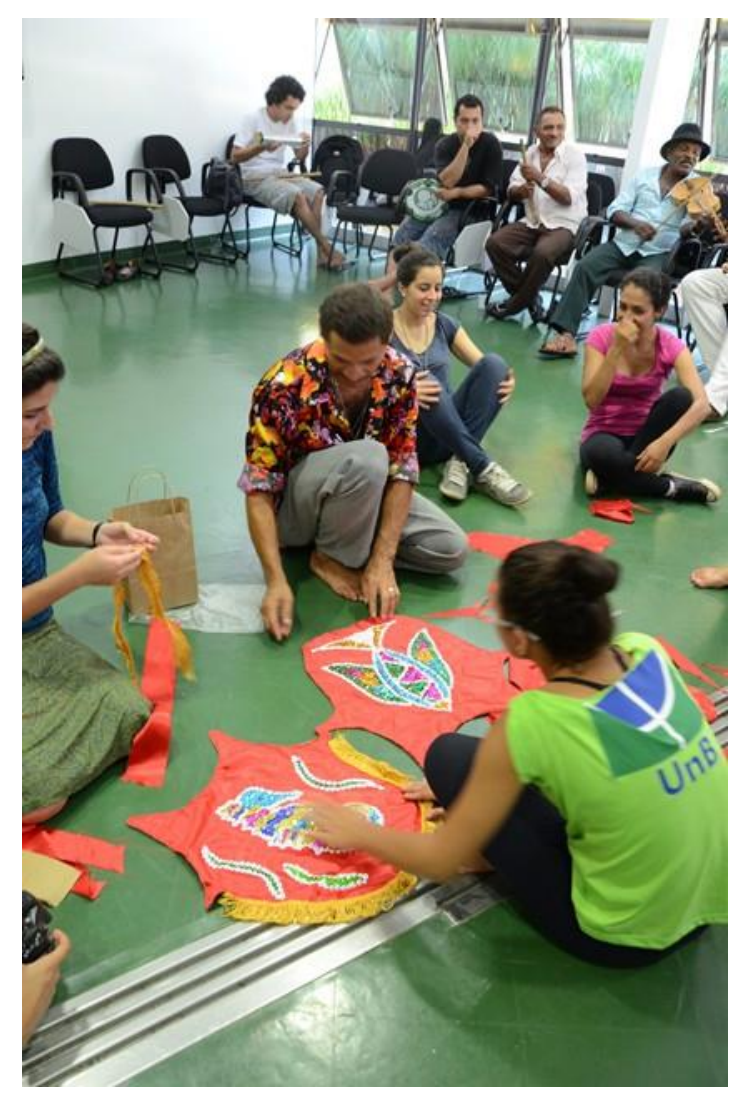

Foto 02: Risoaldo, filho de Mestre Biu, ensinando os alunos a bordar os peitorais usados na brincadeira.

Felizmente no decorrer da disciplina, Mestre Biu pôde exercitar aquilo que sabe e gosta, o Cavalo Marinho. E logo no início já pôs todos para "aquecerem", apesar do calor que fazia em Brasília. Sem maiores preparações, tivemos todos que experimentar o trupé (passo característico da brincadeira, que possui diversas variações rítmicas). Na primeira aula nós, as professoras-parceiras, tentamos sanar nossas duvidas simplesmente perguntando ao Mestre e nos deparamos com nosso próprio despreparo para lidar com aquela outra metodologia de trabalho. Ao perguntarmos: "Mestre, e durante o passo, o que a gente faz com os braços?", Mestre Biu respondeu: "Minhas filhas, vocês podem fazer o que quiserem!". Percebíamos que durante o trupé os braços faziam movimentos específicos e tentávamos codificá-los, compreendê-los cartesianamente: os braços fazem isso, as pernas aquilo. Mestre Biu mostrou que isso não adiantaria de nada. Tínhamos que experimentar para aprender (novamente aqui a noção de "comunidade de prática, de Leave, parece ser bastante adequada para refletir sobre essa forma de aprendizagem).

Depois de duas semanas pudemos perceber que ele estava certo: nossos corpos haviam entendido e nossos braços já começavam a saber o que fazer, integrados ao 
movimento do corpo na dança/brincadeira. Sem falsas dicotomias (corpo-mente, razãoemoção), brincamos todos no ritmo do Cavalo Marinho, não somente compartilhando o conteúdo de uma tradição específica, mas, sobretudo, aprendendo (ou re-aprendendo) que a construção de conhecimentos é muito mais plena quando ocorre de forma coletiva e quando é integralmente vivenciada.

A ideia de que as tradições orais estão intimamente ligadas a tradições corporais vem sendo desenvolvida por diversos pesquisadores (acadêmicos) que finalmente compreenderam que a voz não pode ser descolada do corpo e que os processos de memorização e transmissão de saberes orais envolvem performances específicas ${ }^{6}$. No caso do Cavalo Marinho isso fica claro, por exemplo, na construção das figuras. Cada figura representa um determinado papel (Mateus, Empata Samba, Mané do Baile, Soldado, Véia do Bambu, etc.) e só passa a existir de fato em performance. Sua relação/diálogo com os Mestres e com outras eventuais figuras da brincadeira se dá através de falas específicas. Sua caracterização não se dá apenas através das roupas, máscaras ou maquiagem, mas é também, sobretudo, vocal, textual e corporal. É essa combinação que permite a identificação da figura pelo público. Ou seja, não basta saber o "texto" da figura ou se vestir com suas roupas se você não sabe como "brincar" com ela. Por esse motivo acreditamos que soa empobrecedor estabelecer comparações entre culturas orais e culturas escritas. A própria dicotomia já se constrói sob falsos e absolutamente desiguais termos. É equivocada, pois enquanto a escrita atua como suporte, forma de registro que pode ser pensada e conservada de forma autônoma, a oralidade não existe sem a corporalidade, sem sujeitos em relação, sem performances plenas. Enquanto a escrita é um suporte que pode ser descolado do sujeito/autor, a oralidade é uma forma de estar no mundo, na coletividade.

Na relação com Mestre Biu, em interação com os alunos, vivenciamos plenamente a imbricação entre corporalidade e oralidade. Cantar toadas, declamar loas, participar das danças coletivamente, fez parte do rico aprendizado compartilhado em nossas seis aulas de contato com o Cavalo Marinho Estrela de Ouro. Acompanharam as aulas o grupo de músicos que toca rabeca, pandeiro, baje e mineiro"). Na composição do "banco" uma alusão ao lugar onde os músicos sentam para tocar - embora reduzidos em número para a ocasião, participavam dois filhos de Mestre Biu, Risoaldo e Aguinaldo, o músico Jomar (que também dirige o vídeo), e Luiz Paixão, um grande mestre rabequeiro. Aqui percebemos outro aspecto importante, que parece garantir a continuidade de muitas tradições populares: os vínculos familiares. Risoaldo e Aguinaldo aprendem cotidianamente com o pai as muitas artes e ofícios envolvidos na realização do Cavalo Marinho, atuando naqueles em que demonstram mais habilidade, mas vivenciando e conhecendo, ao longo da vida, toda a brincadeira. Como anotou a aluna Isa Laranjeira Fortes, do Curso de Licenciatura em Artes Cênicas: "O mestre deixou bem claro que o grupo é que faz a brincadeira. (...) 'Nós aqui é tudo um só'." Na segunda edição da disciplina, no segundo semestre de 2011, Mestre Biu chegou muito abatido em Brasília, em função do falecimento recente de um familiar. Na ocasião seu filho Risoaldo, com sensibilidade, num acordo com o pai, assumiu a função de professor e conduziu a turma como só o faria alguém com a devida experiência e técnica para tanto.

Já em relação a como se dá o processo de transmissão saberes fora do Grupo, Mestre Biu Alexandre comenta, em entrevista concedida à UnB TV em 19/11/2010:

Eu vim trazer o meu saber para o Encontro de Saberes. Eu trouxe de Pernambuco para dar para o povo de Brasília. Sonho passar o que eu sei para os alunos, para a

\footnotetext{
${ }^{6}$ Ver, entre outros Hastrup (1994), Zumthor (1993, 2000), Schechner (1988), Turner (1992)

${ }^{7}$ Baje é a denominação usada entre os brincantes de Cavalo Marinho para o reco-reco e mineiro é também conhecido como ganzá.
} 
universidade. A minha parte é de ensinar loa, trupé ${ }^{8}$ e a dança. Tem loa de galante e de mestre. Eu tenho prazer e orgulho de passar o que eu sei. Mas cada um tem uma cabeça para aprender.

Neste fragmento é patente a generosidade e o prazer de Mestre Biu em compartilhar seus conhecimentos com os alunos, com a universidade, a mesma que durante tanto tempo se manteve cerrada e alheia ao seu saber. Nessa mesma fala ele também explicita uma perspectiva metodológica distinta daquela que é comumente utilizada em nossas instituições formais de ensino: "cada um tem uma cabeça para aprender", ou seja, ele tem muita clareza de que cada aluno terá sua história, sua dedicação, seu envolvimento com a brincadeira, e isso inevitavelmente derivará em aprendizados distintos. Essa clareza de que o conhecimento não é algo concreto, que se distribui ou se transmite objetivamente, mas é algo vivo e só existe corporificado, agenciado por pessoas, nos mostrou mais um aspecto da sabedoria do Mestre, auxiliando, sem dúvida, no exercício presente e futuro de nossa profissão.

Ao longo das seis aulas pudemos exercitar o trupé, entoar loas, dançar em roda, confeccionar máscaras, coroas e arcos coloridos. Experimentamos realizar a difícil coreografia dos arcos, comandada pelos apitos de Mestre Biu. Alguns dos alunos também se aventuraram no aprendizado dos instrumentos (mineiro ou ganzá, pandeiro, baje e rabeca). A diversidade de saberes que o grupo detém demonstrou que a separação por campo de saber faz pouco sentido quando se tratam se tradições expressivas. Desta forma, apesar de o Cavalo Marinho, num primeiro momento, ter sido relacionado à área de Artes Cênicas/Teatro (afinal, precisamos dar respostas às instituições das quais fazemos parte) ficou claro que esta brincadeira envolve igualmente a música, a dança, as artes visuais, a literatura, entre tantas outras disciplinas. ${ }^{9}$

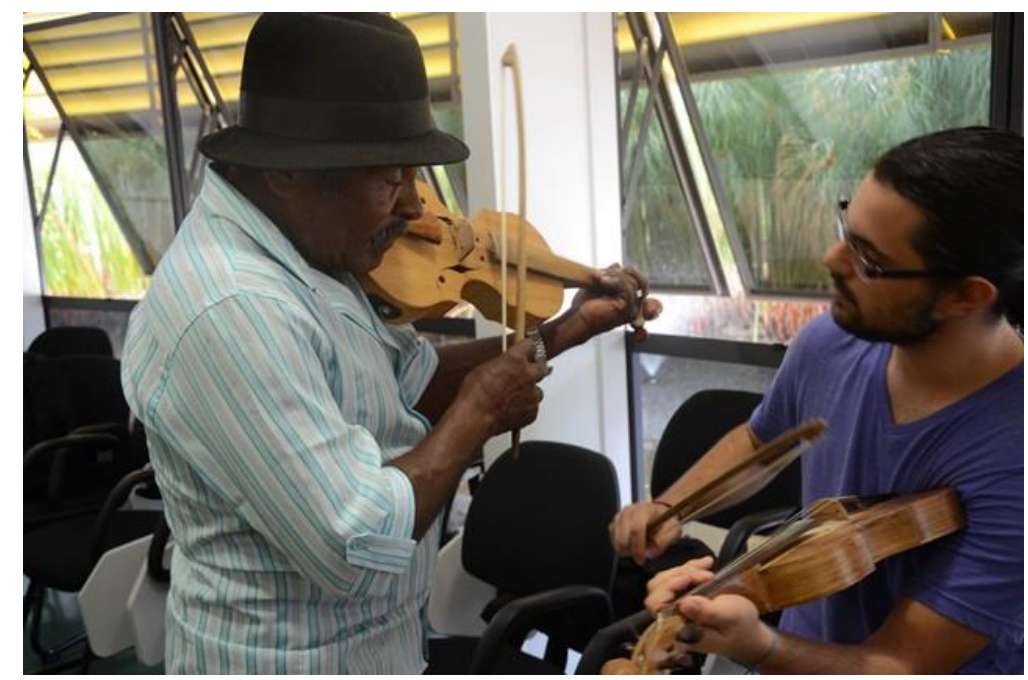

Mestre Luiz Paixão, da rabeca, ensinando aluno da disciplina.

No último dia de aula do Módulo o Mestre insistiu para que os alunos assistissem ao vídeo do Estrela de Ouro (mencionado acima), para que pudessem ver como se realiza uma brincadeira com o Grupo completo. Um dos momentos do vídeo chamou especialmente a atenção de todos: a aparição de Mestre Biu como Caboclo Iorubá. A aluna Adriana Bertolucci, do curso de Letras-Português, relata em seu diário de bordo:

\footnotetext{
${ }^{8}$ Como já foi mencionado no corpo do texto, loa é o verso ou poema falado no Cavalo Marinho e trupé é o passo característico da brincadeira.

9 Sobre a questão do "enquadramento" institucional da diversidade culturas das tradições expressivas, ver o recente artigo de Tibaji (2010).
} 
No final da apresentação vista no vídeo, Mestre Biu entrava em um personagem e participava de um ritual em que ele tirava a roupa e se deitava em algo que representava cacos de vidro. Os alunos ficaram inquietos. Queriam saber como ocorria esse ritual e qual seu significado. Mas Mestre Biu mostrando mais uma vez toda sua sabedoria, os deixou ainda na curiosidade. Disse que aquilo era uma representação de cunho espiritual, e só quem era espírita (sic) para compreender. E que mestres que realmente acreditam e têm essa fé, jamais vão expor o significado que tem para cada um esse momento.

A aluna Maísa Cristina, do Curso de Sociologia, também comenta a esse respeito:

No vídeo vimos um pouco porque o caboclo de Orubá guarda tanto mistério. Ele é interpretado pelo próprio Mestre Biu e, em um determinado momento, esfrega vidro pelo corpo todo e não se corta, chocando toda a turma que assistia ao vídeo. O mestre deu a entender que este era o lado espiritual do cavalo marinho, que só poderia ser explicado por quem vive o personagem.

A relação que se estabelece entre o Mestre Biu Alexandre e a figura do caboclo Ioruba (também conhecido como Arubá ou Orubá), com suas especificidades e conexões espirituais, impregnam de mistério e de um caráter sagrado, a brincadeira e suas derivações. Espaço de silêncio e respeito onde nem tudo deve ser dito e explicado. Lugar da experiência e da troca entre homens e divindades. Outra dimensão do cavalo marinho desvela-se. O que permanecia invisível, sob o colorido, a musicalidade e o ritmo intenso da brincadeira, vinha naquele momento à tona: a espiritualidade.

\section{Caboclo Yorubá}

Vocês me chamam caboclo

Eu não sou caboclo, não

Foi o sol que me queimou

Lá em cima no sertão

(Refrão)

Olê, olê

Olê, Olê, Olá

Ouvi passar o caboclo de Yorubá

Eu vi rodar

Caboclo da minha terra Não

toma água em Coité Quero

me livrar das flechas Dos

caboclos de Canindé

As meninas lá de casa

São um pouco caridosa

Planta rosa, nasce cravo

Planta cravo, nasce rosa

Olê Olê, Olé, olé

Eu vi passar o caboclo de Orubá

Em como naquela serra tem um velho caboclo

Quando vê moça bonita faz sem ponteiro

Nas asas virou sucena

Eu não sei o que tem meus olhos

Que só ama a cor morena.

Lá do céu desceu um cravo

No colo de uma mulata

Eu tava tão perto dela

Que o cravo quase me mata

Lá no pé daquela serra

Tem uma onça amoitada

Se eu morasse perto dela

Matava aquela malvada

Quando eu vim de lá de cima

Me lembrei de Mestre Isídio

Se você me ajudar 
Talvez um dos grandes desafios seja, ao mesmo tempo, manter o fio da tradição, reverenciando a sabedoria ancestral e seguir atualizando a brincadeira no hic et nunc, incorporando os jovens e sua nova visão de mundo. Para finalizar (ou nos despedir), deixamos algumas loas compartilhadas por Mestre Biu com a turma ${ }^{10}$ :

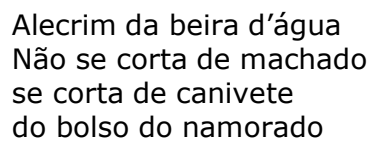

Chegada está a hora, acreditamos, de rever nossas concepções, fortemente arraigadas, de educação disciplinar e de construção de conhecimento estabelecidas pelas epistemologias ocidentais. Ao nos dispormos a compartilhar saberes, numa "aprendizagem situada" que respeite contextos e referenciais culturais específicos (tão ricos e multifacetados num país como o nosso), podemos ampliar não apenas nossas capacidades cognitivas, mas também nossa capacidade de vivenciar outros "mundos possíveis".

Procuramos demonstrar ao longo do artigo que, quando compreendermos que as chamadas "culturas populares" possuem acervos técnicos específicos e consistentes, como nos alerta Beti Rabetti, que a hierarquização de saberes mencionada pela aluna Gabriela está a serviço de uma hierarquização política e econômica que interessa a apenas uma parcela da sociedade, que as tradições orais estão intimamente ligadas a tradições corporais/expressivas (ou "conhecimentos incorporados", como propõe com Hastrup) e que a noção de "disciplina", no sentido de área ou campo de saber deve ser dilatada e transformada para que possa abranger outras formas de conhecimento, possivelmente então consigamos realizar ações concretas de inclusão e acolhimento dos saberes tradicionais, indígenas e afro-brasileiros nas salas de aula.

Como nos disse Mestre Biu, "precisamos saber para gostar", e só podemos ter acesso, de fato, a essa imensa gama de conhecimentos, quando eles entrarem, devidamente legitimados, pela porta da frente de nossas universidades.

Referências bibliográficas:

ABREU, Joana. Catirina, o Boi e sua Vizinhança - elementos da performance dos folguedos populares como referência para os processos de formação do ator. Dissertação (Mestrado em Artes), Instituto de Artes da Universidade de Brasília, 2006.

\footnotetext{
${ }^{10}$ A disciplina Artes e Ofícios dos Saberes Tradicionais teve sua $3^{a}$ edição no $2^{\circ}$ semestre de 2012. Mestre Biu e seus companheiros do "banco" continuam contribuindo de maneira inestimável com essa experiência de troca, de ensino e aprendizagem de seus saberes na universidade.
} 
ACSELRAD, Maria. Viva Pareia! A arte da brincadeira ou a beleza da safadeza: uma abordagem antropológica da estética do Cavalo Marinho. Dissertação de Mestrado em Antropologia, UFRJ/IFCS, Rio de Janeiro, 2002.

CARVALHO, José Jorge de. Metamorfoses das tradições performáticas afro-.. brasileiras: de patrimônio cultural a indústria do entretenimento. In: FUNARTE-.IPHAN. Celebrações e saberes da cultura popular: pesquisa, inventário, crítica, perspectivas. Brasília: CNFCP, 2004. p. 65-38. . Por que e como Apoiar as Culturas Populares. In: Hamilton Faria; Ricardo Lima. (Org.). $F$

omento, Difusão e Representação das Culturas

Populares. São Paulo; Brasília: Instituto Pólis; Ministério da Cultura, 2006, p. 12-28.

. Espetacularização e Canibalização das Culturas Populares na América Latina. In: Ari Pedro. (Org

.). Latinidade da América Latina. Enfoques

socioantropológicos. São Paulo: Editora Hucitec, 2008, p. 265--292.

HASTRUP, Kirsten. Anthropological knowledge incorporated: discussion. In: HASTRUP, K; HERVIK, Peter (orgs.) Social Experience and Anthropological Knowledge London: Routledge, 1994.

LAVE, J. Teaching, as Learning. Practice. Mind, Culture, and Activity. v.3, n.3, 1996, p. 149-164.

LAVE, Jean, WENGER, Etienne. Situated Learning. Cambridge: Cambridge University Press (CUP), 1991.

LEWINSOHN, Ana Caldas. O Ator Brincante: no contexto do Teatro de Rua e do Cavalo Marinho. Dissertação (Mestrado em Artes). UNICAMP, 2009.

OLIVEIRA, Érico José Souza de. A Roda do Mundo Gira: um olhar sobre o Cavalo Marinho Estrela de Ouro (Condado - PE). Recife: Ed. SESC, 2006.

OLIVEIRA, Mariana Silva. O Jogo da Cena do Cavalo Marinho: Diálogos entre Teatro e Brincadeira. Dissertação (Mestrado em Teatro), Centro de Letras e Artes, Universidade Federal do Rio de Janeiro, 2006.

RABETTI, Beti. Memória e Culturas do popular no teatro: o típico e as técnicas. 0 Percevejo - Teatro e Cultura Popular. Ano 8, n. 8, 2000, p. 3-18.

TENDERINI, Helena Maria. Na Pisada do Galope: Cavalo Marinho na fronteira traçada entre Brincadeira e Realidade. Dissertação (Mestrado em Antropologia Social).

Universidade Federal de Pernambuco, 2003.

SCHECHNER, Richard. Performance Theory. New York and London: Routledge, 1988.

TIBAJI, Alberto. Teatro, valor e pluralidade: rumo a uma política e a uma estética do popular. In: RABETII, Beti (org.). Teatro e Comicidades 3: facécias, faceirices e divertimentos. Rio de Janeiro: 7Letras, 2010. p: 13-21.

TURNER, Victor. The Anthropology of Performance. 2a. ed. New York: PAJ Publications, 1992.

ZUMTHOR, Paul. A Letra e a Voz - a

"literatura"medieval. Tradução de Amálio pinheiro e Jerusa Pires Ferreira. São Paulo: Companhia das L etras, 1993.

Performance, Recepção,

Leitura. Tradução de Jerusa Pires Ferreira e Suely Fenerich. São Paulo: EDUC, 2000.

Vídeo: 
CAVALO Marinho Estrela de Ouro. Direção Jomar Jr.; produção José Saturnino de Araújo. Recife: ADCE Produções, 2007.

Luciana Hartmann (Unb/DF)

Rita de Almeida Castro (Unb/DF)

Recebido em: 06/11/2012

Aprovado em: 13/02/2013 